\title{
Hydrological changes after the 2016 Kumamoto earthquake, Japan
}

\author{
Naoji Koizumi ${ }^{* *}$, Shinsuke Minote ${ }^{2}$, Tatsuya Tanaka ${ }^{3}$, Azumi Mori ${ }^{4}$, Takumi Ajiki ${ }^{5}$, Tsutomu Sato ${ }^{6}$, \\ Hiroshi A. Takahashi ${ }^{6}$ and Norio Matsumoto ${ }^{6}$
}

\begin{abstract}
The 2016 Kumamoto earthquake, whose main shock was an M7.3 event on April 16, 2016, 28 h after a foreshock of M6.5, caused severe damage in and around Kumamoto Prefecture, Japan. It also caused postseismic hydrological changes in Kumamoto Prefecture. In this study, we analyzed daily streamflow data collected by eight observation stations from 2001 to 2017 in regions that experienced strong ground motion during the 2016 Kumamoto earthquake. We also surveyed 11 water springs in the region several times after the main shock. Streamflow had no or slight change immediately after the earthquake; however, large increases were recorded at some of the eight stations following a heavy rainfall that occurred 2 months after the earthquake. A decrease in the water-holding capacity of the catchment caused by earthquake-induced landslides can explain this delayed streamflow increase. Conversely, earthquake-related changes to the spring flow rate were not so clear. Water temperature and chemical composition of spring waters were also hardly changed. Only the concentration of $\mathrm{NO}_{3}{ }^{-}$, which is usually considered to be supplied from the surface, changed slightly just after the earthquake. These results show that the postseismic hydrological changes were caused mainly by earthquake-induced surface phenomena and that there was little contribution from hydrothermal fluid.
\end{abstract}

Keywords: Kumamoto earthquake, Hydrological changes, Streamflow, Spring, Groundwater, Water-holding capacity

\section{Introduction}

Large earthquakes are well known to sometimes cause wide hydrological changes in regions affected by strong ground motion (e.g., Waller 1966). In several cases of such changes, streamflow and spring flow increased in lowlands and the water table dropped in highlands. Rojstaczer and Wolf (1992) and Rojstaczer et al. (1995) comprehensively explained those changes related to the 1989 Loma Prieta earthquake with permeability enhancement. Sato et al. (2000) also used permeability enhancement to explain postseismic groundwater changes after the 1995 Kobe earthquake. However, an analysis of postseismic hydrographs of rivers affected by several large earthquakes, including the 1989 Loma Prieta earthquake, showed that the hydrological changes were caused by

\footnotetext{
*Correspondence: koizumi.n@ses.usp.ac.jp

1 School of Environmental Science, The University of Shiga Prefecture,

2500, Hassaka-cho, Hikone, Shiga 522-8533, Japan

Full list of author information is available at the end of the article
}

liquefaction and not permeability effects (Manga 2001).

However, liquefaction seems to be an unlikely cause of water table drops in highlands and large and long postseismic increases in stream water. Actually, in the 1999 Chi-Chi earthquake in Taiwan, no postseismic flow rate increase was found in a certain stream, although heavy liquefaction occurred in the catchment area of the stream (Wang et al. 2004). The observed increases in streamflow and spring flow in lowlands, and the water table drop in highlands, following the 1999 Chi-Chi earthquake may be explained by enhanced vertical permeability in the mountain region, a phenomenon that has less effect on hydrographs (Wang et al. 2004; Wang and Manga 2015). Alternatively, Montgomery et al. (2003) suggested that co-seismic volumetric strain changes may have contributed to postseismic streamflow changes after the 2001 Nisqually earthquake (Mw6.8).

Because Japan is relatively rich in water resources, people may have not paid much attention to earthquake-related hydrological changes. But those 
hydrological changes are clearly one of the seismic risks and should also be examined in Japan because those changes sometimes continue for a period of several months to years (Rojstaczer and Wolf 1992; Sato et al. 2000).

The 2016 Kumamoto Earthquake, which occurred mainly in Kumamoto Prefecture, Japan, in April 2016 (Hirata 2016; Hashimoto et al. 2017), caused severe damage in and around Kumamoto Prefecture. It also caused many changes in stream water and groundwater (Sato et al. 2017; Ichiyanagi and Ando 2017; Hosono et al. 2019). The 2016 Kumamoto earthquake had two main events: Japan Meteorological Agency (JMA) magnitude (Mj) 6.5 foreshock at 21:26 Japan Standard Time on April 14, 2016, and the main shock of Mj 7.3 at 01:26 on April 16, 2016. These earthquakes and their aftershocks occurred mainly along the Futagawa and northern Hinagu faults. ENE-trending surface ruptures approximately $30 \mathrm{~km}$ long appeared along these faults and reached the Aso caldera (Shirahama et al. 2016) (Fig. 1). The region of strong ground motion of the main shock spreads from the coastal plain to the Aso caldera (Fig. 1).

In this paper, we report the postseismic hydrological changes related to the 2016 Kumamoto earthquake.

\section{Methods}

\section{Streamflow data}

The region of strong ground motion during the main shock contains three main river systems: Shira River system, Midori River system, and Kikuchi River system (Fig. 1). We obtained data for these rivers from the water information system of the Ministry of Land, Infrastructure, Transport and Tourism (2019). In January 2019, flow rate data were available up to December 2017. Therefore, we obtained streamflow data collected by eight observation stations along the three river systems during the period 2001-2017. These eight stations have measured streamflow since 2001 or earlier, with no long data gaps through the end of the study period.

\section{Spring water measurement}

We surveyed the 11 water springs shown in Fig. 1 six to nine times for flow rate, temperature, and chemistry during the period April 16, 2016, to November 2017. The sampling intervals were a few weeks to several months. The initial surveys were performed several days to 1 month after the April 16, 2016, main shock. Fortunately, 8 of the 11 springs were also surveyed 1 month to a few years before the 2016 Kumamoto earthquake, although the flow rate of one of these eight springs was

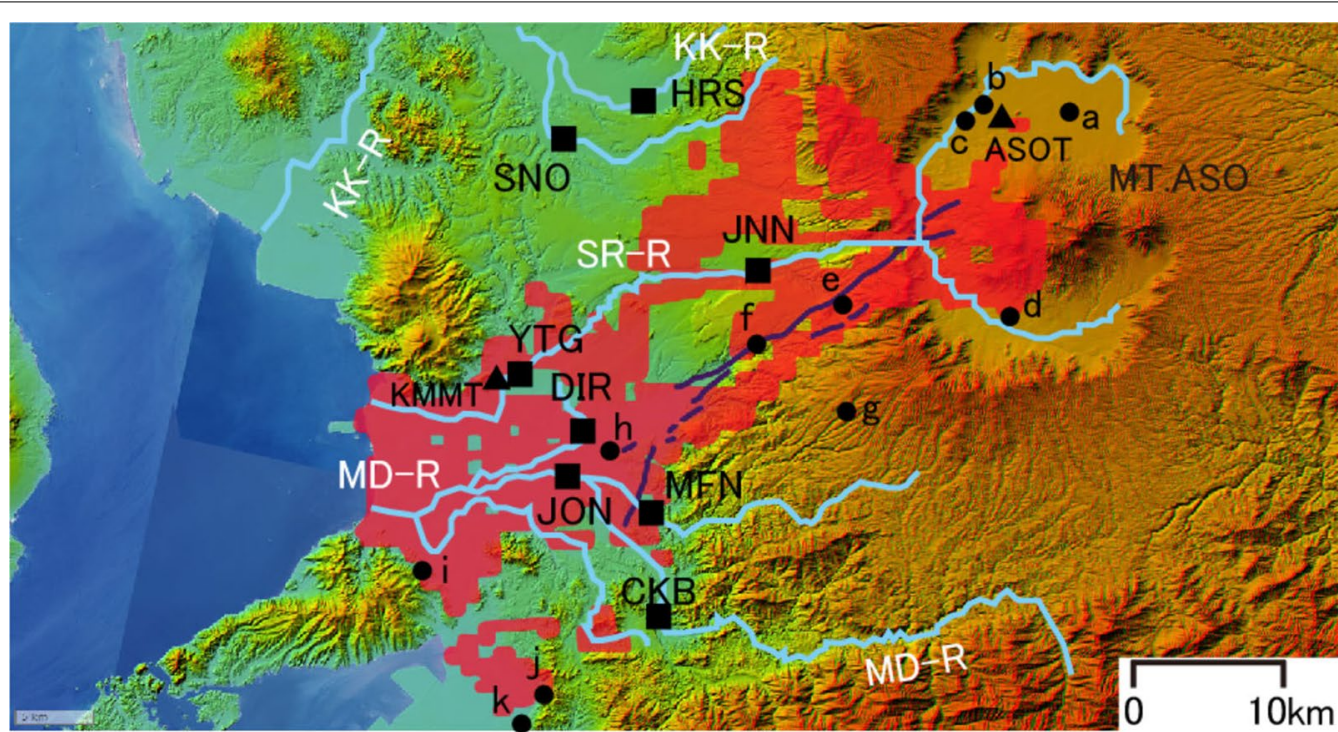

Fig. 1 Map of the study area. Red areas indicate strong ground motion, where the seismic intensity of the main shock of the 2016 Kumamoto earthquake was in the upper 6 range on the JMA scale (Japan Meteorological Agency 2019a). Dark blue lines indicate surface ruptures formed during the earthquake (Shirahama et al. 2016). Light blue lines indicate the three major river systems in the study area: Kichichi River system (KK-R), Shira River system (SR-R), and Midori River system (MD-R). Solid triangles indicate weather stations: Kumamoto Local Meteorological Observatory (KMMT) and Aso-otohime Automated Meteorological Data Acquisition System (ASOT). Solid squares indicate streamflow rate observation stations: SNO, HRS, JNN, YTG, DIR, JON, MFN, and CKB. Solid circles indicate observed springs: a:YKI, b:TNB, c:KYH, d:IKN, e:SOY, f:SOI, g:YSM, h:SMR, i:TDR, j:MTR and k:DMZ. The background map was derived from the Geospatial Information Authority of Japan (2019) 
not measured before the 2016 Kumamoto earthquake. Therefore, we can evaluate the postseismic flow rate changes at 7 of the 11 springs. We can also evaluate postseismic changes in water temperature and chemical composition at 8 of the 11 springs.

\section{Meteorological data}

We obtained daily precipitation data from the Kumamoto Local Meteorological Observatory (KMMT in Fig. 1) and the Aso-otohime AMeDAS or the Aso-otohime Automated Meteorological Data Acquisition System (ASOT in Fig. 1) from the JMA database (Japan Meteorological Agency 2019b). The daily precipitation is generally larger at ASOT than at KMMT, but the patterns are similar.

\section{Analysis to remove effects of precipitation on streamflow}

We calculated the accumulated precipitation and flow rate at all the stations except SNO in the period 20012015, during which no large earthquakes occurred (Fig. 2). At SNO, the calculation was done for data from 2007 to 2015 because there were a lot of missing data at SNO in 2006. We then performed correlation analysis and found a clear linear relationship between these parameters. We removed the effect of the average accumulated precipitation on the accumulated flow rate, to examine the change in the rest accumulated flow rate over time.

We also calculated relative precipitation by estimating the average accumulated precipitation. We applied an approximately straight line to the accumulated precipitation data from 2001 to 2015, as shown in Fig. 2b. This straight line is the average accumulated precipitation. We then subtracted the average accumulated precipitation from accumulated precipitation, leaving relative precipitation as the remainder.

\section{Estimation of temporal streamflow response to precipitation}

The streamflow response to precipitation depends on catchment wetness, which we estimated using the antecedent precipitation index (API; Mosley 1979). For example, API(10) is calculated as follows:

$$
\operatorname{API}(10)=P_{1} / 1+P_{2} / 2+\cdots+P_{10} / 10=\sum_{i=1}^{10} \frac{P_{i}}{i},
$$

where $P_{i}$ is the daily precipitation $i$ days before the current day. In this study, we used hourly data to estimate $\operatorname{API}(10) . P_{i}$ was then calculated as follows:

$$
P_{i}=\sum_{K=24 i-23}^{24 i} r_{k}
$$

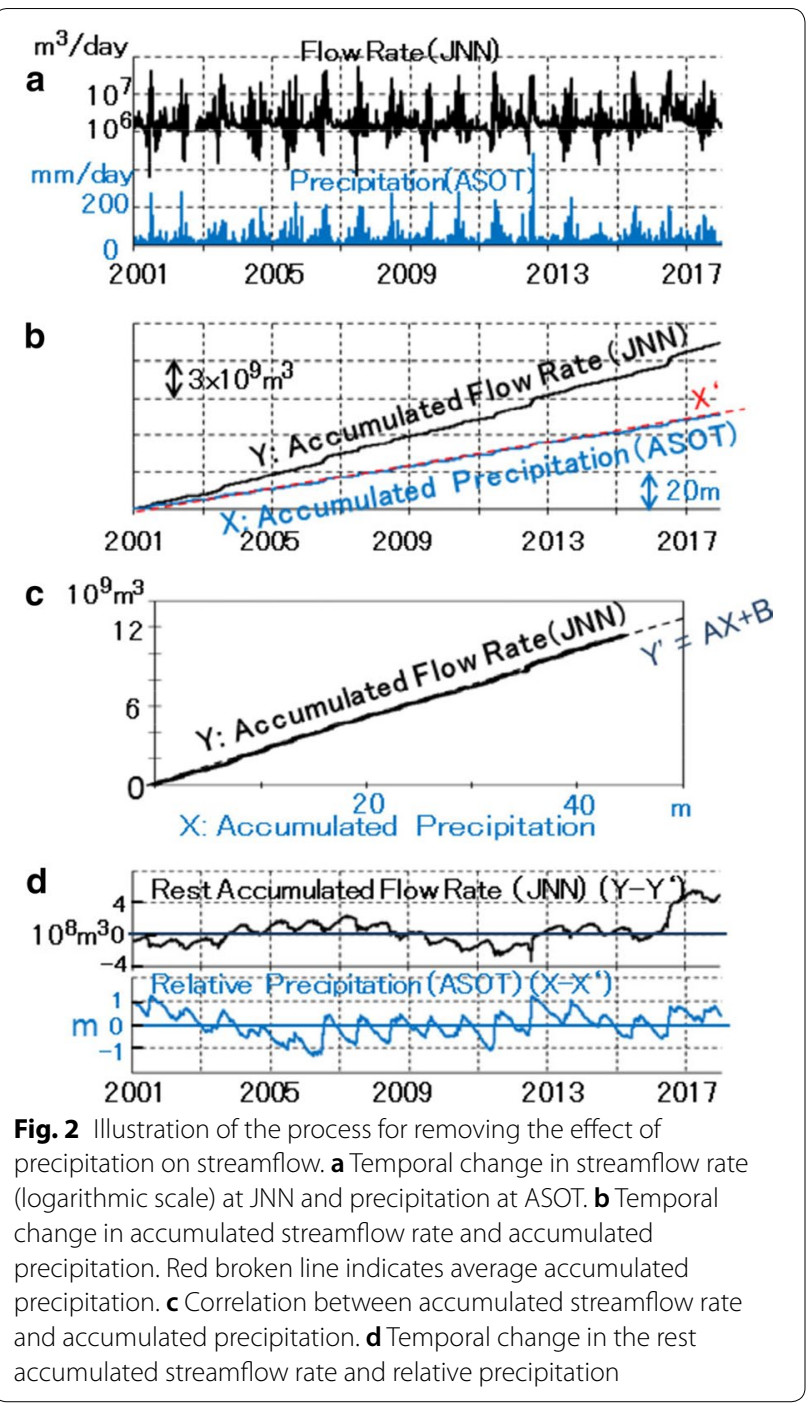

where $r_{k}$ is the hourly precipitation $k$ hours before the current time.

The temporal change in streamflow response to precipitation was estimated when the following four conditions were satisfied:

1. Precipitation was $\geq 20 \mathrm{~mm}$ and $\leq 100 \mathrm{~mm}$ at both KMMT and ASOT, because a small amount of precipitation produces no clear direct runoff and because a large amount of precipitation causes an irregular streamflow response.

2. API $(10) \leq 10 \mathrm{~mm}$ both at KMMT and ASOT at the start of precipitation.

3. Direct runoff had finished flowing, followed by several hours of stable streamflow at the same rate observed prior to the start of precipitation $\pm 5 \mathrm{~m}^{3} / \mathrm{s}$. 
4. The ratio of precipitation at ASOT to that at KMMT was $\geq 0.8$ and $\leq 2.0$, because very local precipitation produces an irregular streamflow response and because the accumulated precipitation at ASOT during the period 2001-2017 was 1.5 times larger than that at KMMT.

When these four conditions were satisfied, we identified the start and end points of direct runoff, connected these points with a straight line, and estimated the direct runoff volume (Fig. 3a). Repeating this process yielded a graph of the correlation between direct runoff and precipitation at each streamflow observation station (Fig. 3b). The direct runoff volume could not be estimated when precipitation was continuous. For this reason, the streamflow response to precipitation during the rainy season was difficult to estimate.

\section{Results}

\section{Streamflow rate}

Daily flow rates recorded at the eight stations in Fig. 1, from 2001 to 2017 are shown in Fig. 4. Precipitation is seen to increase the flow rates, which later decrease again. Therefore, the flow rates generally spiked when precipitation events occurred. At some of the eight stations, flow rates dropped from April to September every

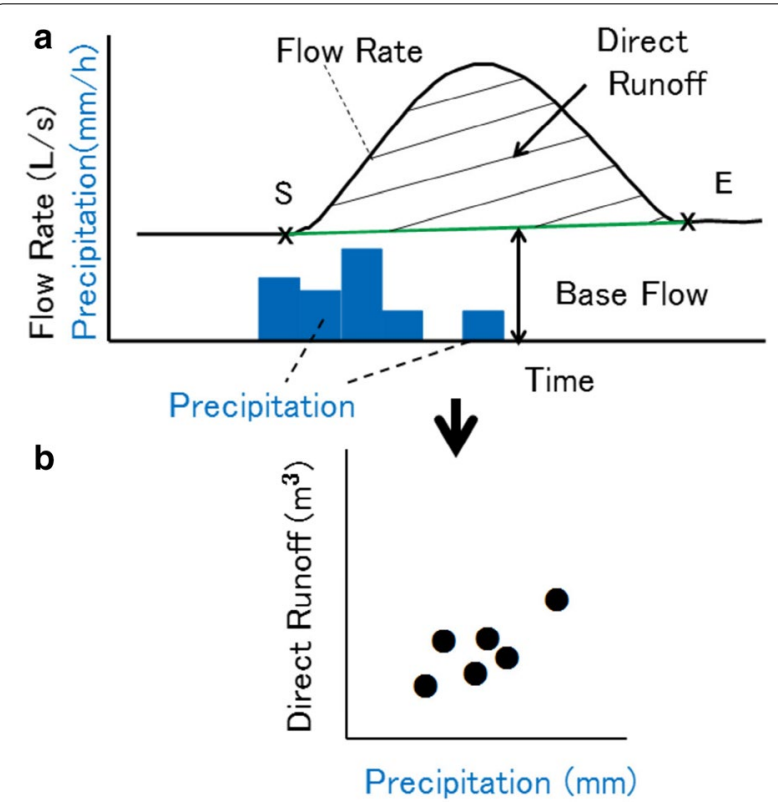

Fig. 3 Schematic hydrograph showing the separation of baseflow and direct runoff. a Separation of baseflow and direct runoff. All precipitation between the start $(S)$ and end $(E)$ points is added to one precipitation series that causes direct runoff. $\mathbf{b}$ Correlation between direct runoff and precipitation year due to the irrigation of paddy, which is the main agricultural method in Japan. These changes made it difficult to identify earthquake-related flow rate changes. Despite this obstacle, the minimum envelope of the flow rate appears to have increased at some stations, especially at JNN, following the main shock of the 2016 Kumamoto earthquake. JNN is upstream of the Shira River, whose main catchment area includes the Aso caldera (Fig. 1). Such postseismic flow increases could be also recognized at SNO, YTG, and DIR (Fig. 4). At HRS, JON, MFN, and $\mathrm{CKB}$, the postseismic flow increases were nearly undetectable (Fig. 4).

\section{Rest accumulated flow rate of the streams}

The temporal changes in the rest accumulated flow rate at each observation station from 2001 to 2017 are shown in Fig. 5. Annual changes were observed at some stations, likely due to delays in precipitation-induced changes in flow rate. The rest accumulated flow rate at all of the eight stations had no or slight change immediately after the main shock. However it had much larger increase 2 months afterward, following a heavy rainfall (Fig. 5). At JNN and SNO, the rest accumulated flow rate increased by more than three times the standard deviation.

\section{Temporal change in streamflow response to precipitation}

Following the 2016 Kumamoto earthquake, the ratio of direct runoff volume to precipitation, which is shown by each solid circle in Fig. 6, tended to be larger at SNO, JNN, YTG, DIR, and MFN, especially during precipitation events above a certain threshold (Fig. 6). The threshold probably depends on the environment around each station. This tendency means that the water-holding capacity of the catchment were reduced after the 2016 Kumamoto earthquake. It seems that the streamflow response to precipitation at JNN, YTG, and MFN in 2017 returned to its historical response before the 2016 Kumamoto earthquake.

\section{Flow rate at springs}

The flow rate changes at the 11 springs are shown in Fig. 7a, b. At 7 of the 11 springs, we determined whether the flow rate of spring water changed before and after the 2016 Kumamoto earthquake as described in "Spring water measurement". At the first sampling date just after the main shock, the flow rate increased at three of the seven springs (e:SOY, g:YSM and k:DMZ), decreased at two of them (f:SOI and h:SMR), and showed no change at two of them (a:YKI and d:IKN). The seasonal changes were also recognized at e:SOY, f:SOI, g:YSM, h:SMR, i:TDR, and $\mathrm{k}: \mathrm{DMZ}$. (Note that the lowercase letters at the beginning of each spring identifier correspond to the location labels given in Fig. 1.) 


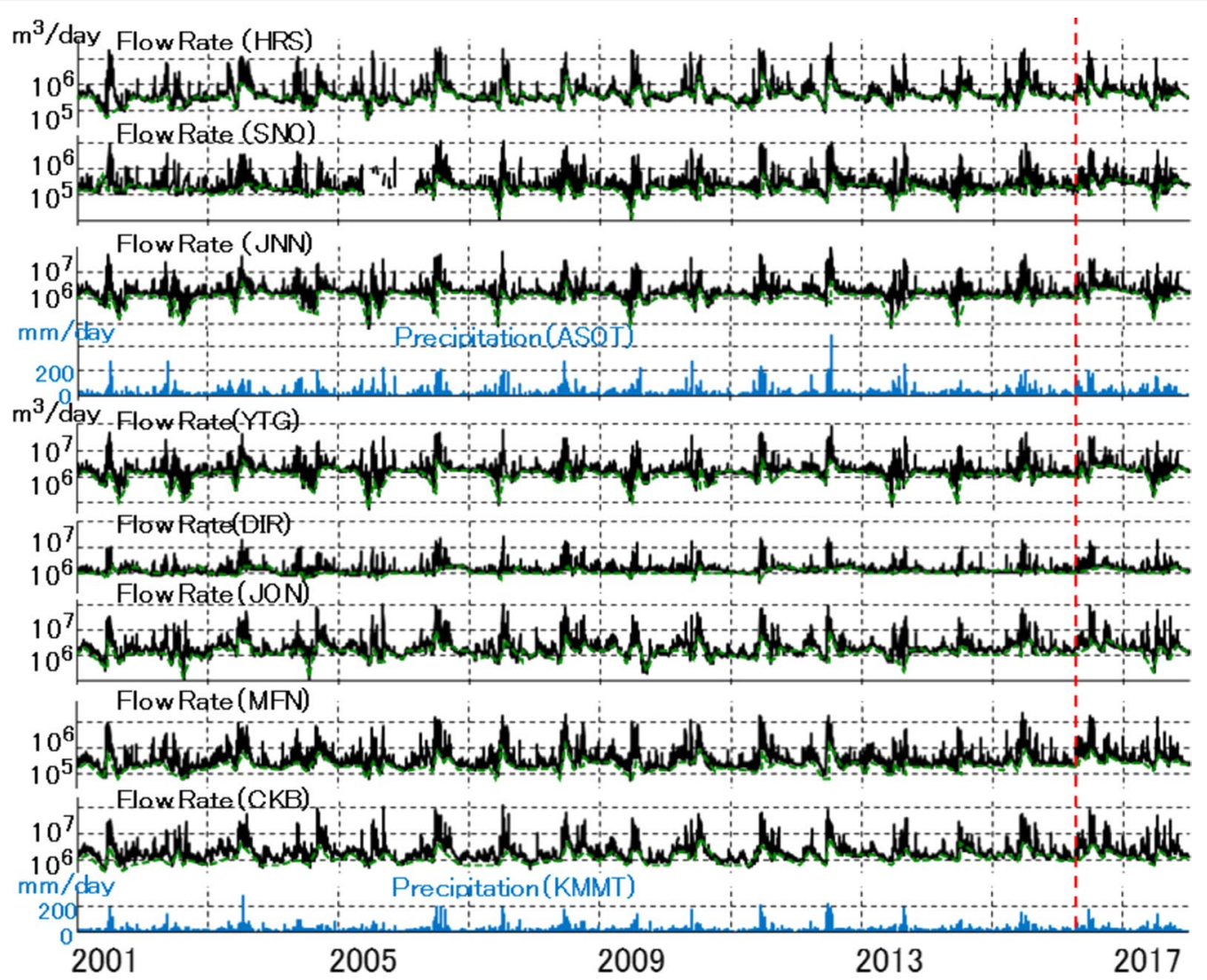

Fig. 4 Daily streamflow rate and precipitation from 2001 to 2017. Vertical red broken line indicates the occurrence of the main shock of the 2016 Kumamoto earthquake. Green broken line shows the minimum envelope of the flow rate

Water temperature and chemical composition of the spring water

Before and after the 2016 Kumamoto earthquake, water temperature and chemical composition changed only slightly in the eight springs for which the comparison could be made (Figs. 8 and 9). Only the concentration of $\mathrm{NO}^{3-}$ was somewhat increased at most of the eight springs just after the earthquake and it soon decreased (Fig. 10).

\section{Discussion}

\section{Streamflow rate}

If the increases in postseismic streamflow had been caused by earthquake-related permeability enhancement, then the streamflow would have increased immediately after the earthquake (e.g., Rojstaczer and Wolf 1992). Therefore, permeability enhancement did not cause the streamflow increase observed 2 months after the 2016 Kumamoto earthquake. Co-seismic volumetric effects (Montgomery et al. 2003) and liquefaction (e.g., Manga 2001) also cannot explain the delayed postseismic streamflow increase in this region. Hosono et al. (2019) reported both of co-seismic drops and rises in stream water level. Similar changes are also recognized in Fig. 5. However those changes were much smaller than the delayed postseismic streamflow increase.

The postseismic decreasing trend in water-holding capacity within the catchment following the earthquake is shown in Fig. 6. The 2016 Kumamoto earthquake caused many landslides in and around the Aso caldera (Miyabuchi 2016); these landslides are expected to have decreased the water-holding capacity of the catchment. Such a phenomenon would cause abnormal increases in postseismic streamflow with heavy precipitation, and an overall increase in the streamflow rate at some flow rate stations in the region. 


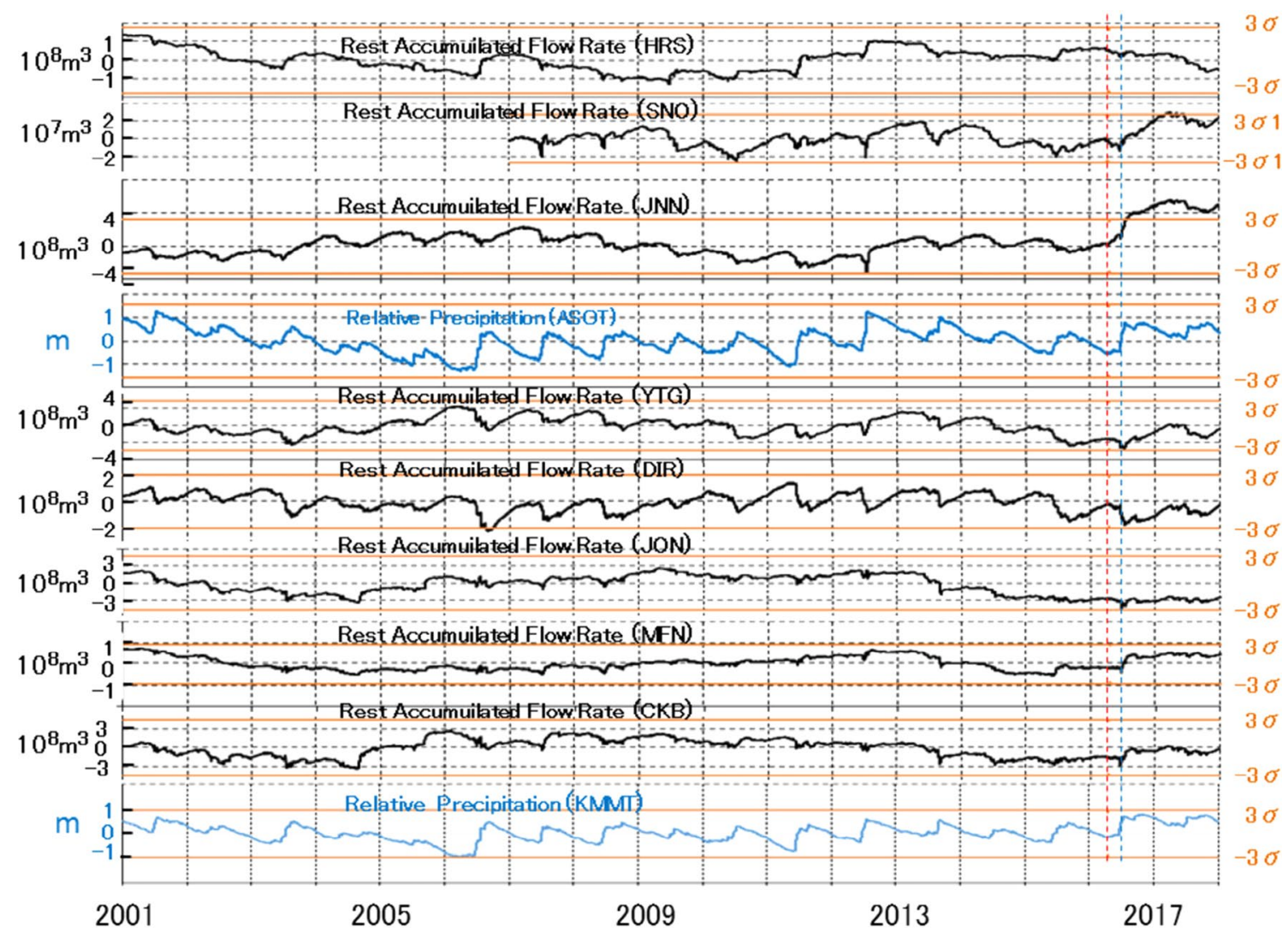

Fig. 5 Temporal change in the rest accumulated flow rate and relative precipitation from 2001 to 2017. $\sigma$ is the standard deviation from 2001 to 2015. $\sigma_{1}$ at SNO is the deviation from 2007 to 2015. Vertical red and blue broken lines indicate the occurrence of the main shock of the 2016 Kumamoto earthquake and of the heavy rainfall 2 months after it, respectively

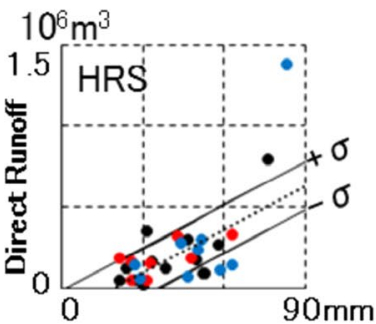

Precipitation (ASOT)

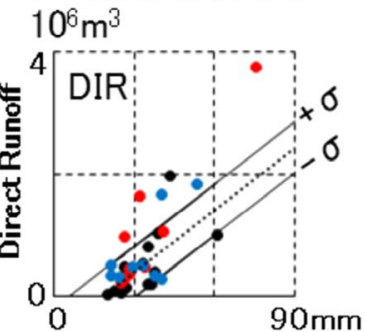

Precipitation (KMMT)

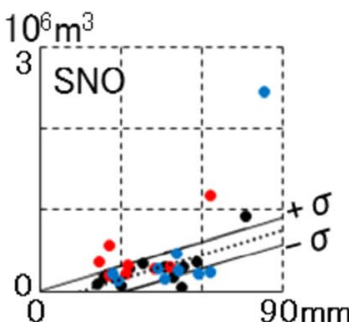

Precipitation (ASOT)

$10^{6} \mathrm{~m}^{3}$

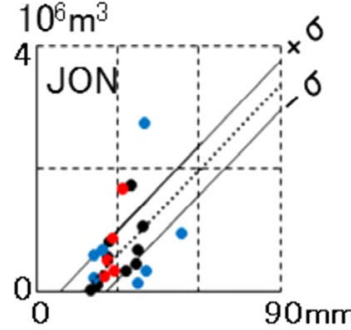

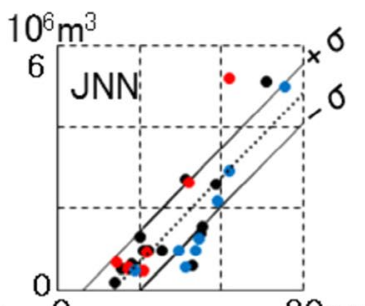

$90 \mathrm{~mm}$

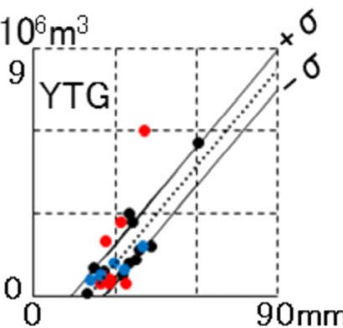

Precipitation (ASOT)

$10^{6} \mathrm{~m}^{3}$

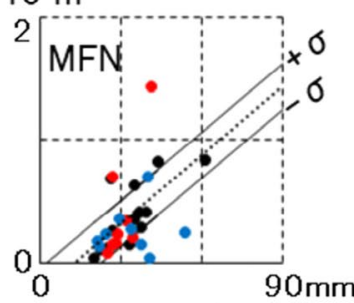

$90 \mathrm{~mm}$

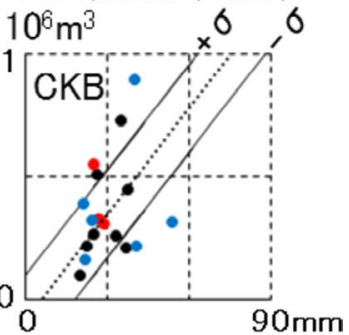

Precipitation (KMMT)

Fig. 6 Temporal change in streamflow response to precipitation. Solid black circles indicate the response from January 1, 2014, to April 13, 2016. Solid red circles indicate the response from April, 14, 2016, when the 2016 Kumamoto earthquake started, to December 31, 2016. Solid blue circles indicate the response from January 1,2017, to December 31, 2017. Black dotted lines indicate the average correlation between precipitation and direct runoff from January 1, 2014, to April 13, 2016. $\sigma$ is the standard deviation of the average correlation during the same period 


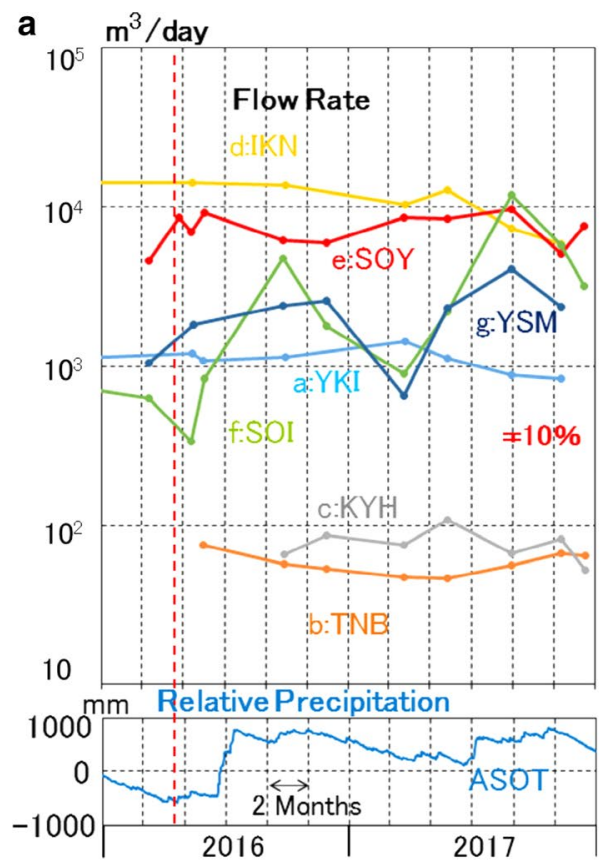

b $\mathrm{m}^{3} /$ day

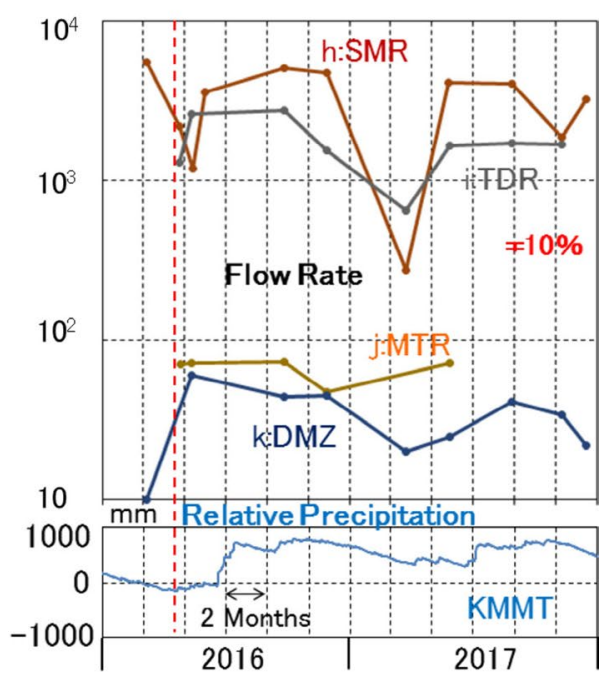

Fig. 7 a Flow rate changes at the springs a:YKI, b:TNB, c:KYH, d:IKN, e:SOY, f:SOI, and g:YSM and the relative precipitation at ASOT during the period from 2016 to 2017. The flow rate was manually measured and its precision was estimated to be about a few to $10 \%$. Vertical red broken line indicates the occurrence of the main shock of the 2016 Kumamoto earthquake. At the springs a:YKI, d:IKN, e:SOY, f:SOI, and g:YSM, the flow rate was measured before the 2016 Kumamoto earthquake. Before 2016 at a:YKI, d:IKN, and f:SOI, the flow rate was respectively measured on February 1, 2014; September 6, 2014; and February 1, 2014. b Flow rate changes at the springs h:SMR, i:TDR, $\mathrm{j}: M T R$, and k:DMZ and the relative precipitation at KMMT during the period 2016-2017. The precision is about a few to $10 \%$. Vertical red broken line indicates the occurrence of the main shock of the 2016 Kumamoto earthquake. At the springs h:SMR and k:DMZ, the flow rate was measured before the 2016 Kumamoto earthquake

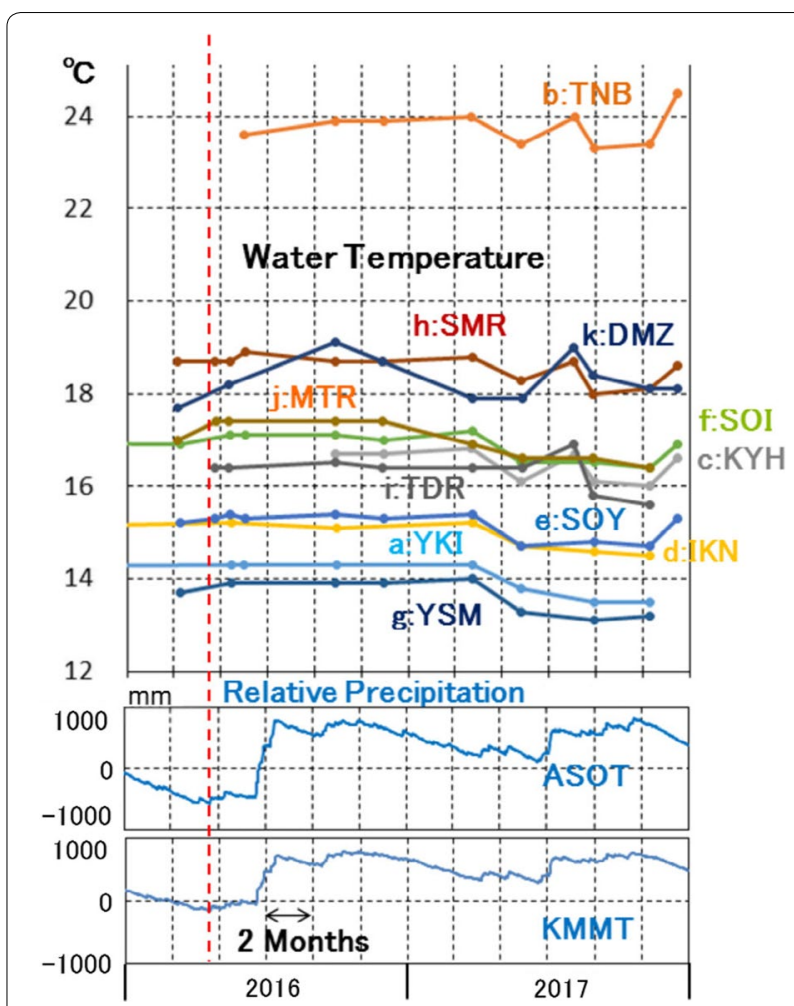

Fig. 8 Water temperature changes at the 11 observed springs and the relative precipitation at ASOT and KMMT during the period 20162017. Before 2016 at a:YKI, d:IKN, and f:SOI, the temperature was, respectively, measured on February 1, 2014; September 6, 2014; and February 1, 2014. The precision of the temperature measurements is $0.1^{\circ} \mathrm{C}$. Vertical red broken line indicates the occurrence of the main shock of the 2016 Kumamoto earthquake

\section{Spring water}

Relative to the flow rate before the 2016 Kumamoto earthquake, it rose at three of the seven springs (e:SOY, g:YSM, and k:DMZ) and dropped at two of them (f:SOI and h:SMR) (Fig. 7). Hosono et al. (2019) also reported both of co-seismic rises and drops in groundwater level. However, large seasonal changes, which were probably induced mainly by precipitation, were recognized at e:SOY, f:SOI, g:YSM, h:SMR, and k:DMZ. Our sampling interval was much longer than that of Hosono et al. (2019). Therefore, the postseismic flow rate changes in Fig. 7 could not be clearly attributed to the earthquake.

Before and after the 2016 Kumamoto earthquake, water temperature and chemical composition were almost stable at the observed springs. Only the concentration of $\mathrm{NO}_{3}{ }^{-}$was somewhat increased just after the earthquake and it soon decreased. Similar results in other groundwaters were also reported by Kawagoshi et al. (2018). $\mathrm{NO}_{3}{ }^{-}$ in groundwater is generally considered to be derived from the surface. Therefore, it seems that supply from the 


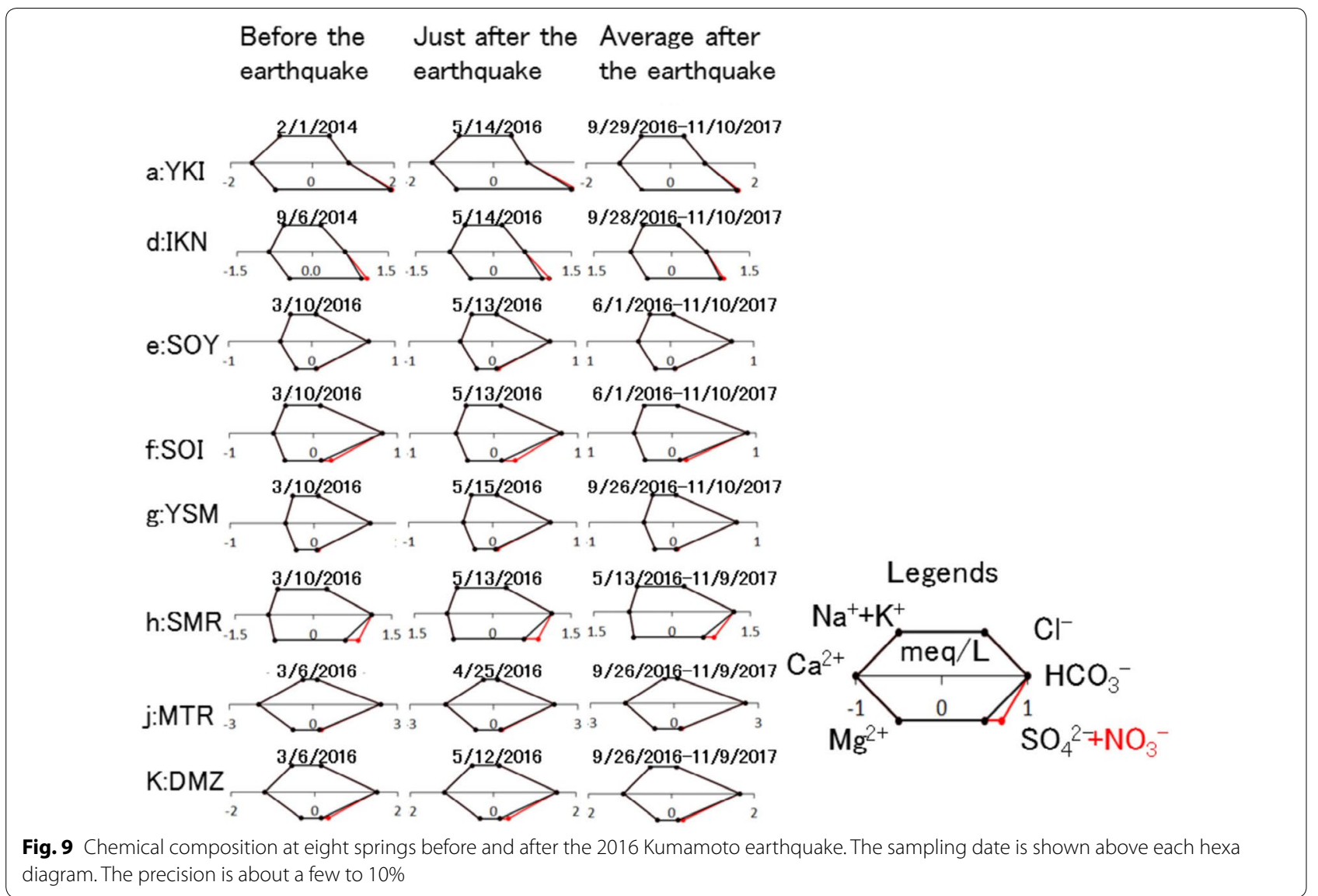

shallow groundwater to the spring was slightly increased and then decreased after the earthquake. These results show that hydrothermal fluid did not enter the spring waters after the 2016 Kumamoto earthquake.

\section{Conclusions}

We analyzed streamflow data from eight observation stations on three major rivers in Kumamoto Prefecture for the period 2001-2017. We also surveyed 11 water springs in the region several times after the main shock. Some of the eight observation stations recorded large increases in streamflow following a heavy rainfall that occurred 2 months after the earthquake. This may be due to a decrease in the water-holding capacity of the catchment caused by earthquake-induced landslides. In contrast, earthquake-related changes in the spring flow rate were not so clear. Water temperature and chemical composition of the spring waters also changed very little. Only the concentration of $\mathrm{NO}_{3}{ }^{-}$, whose origin is usually considered to be the surface, changed slightly just after the earthquake. These results show that the postseismic hydrological changes were caused mainly by earthquakeinduced surface phenomena and that there was little contribution from hydrothermal fluid. 


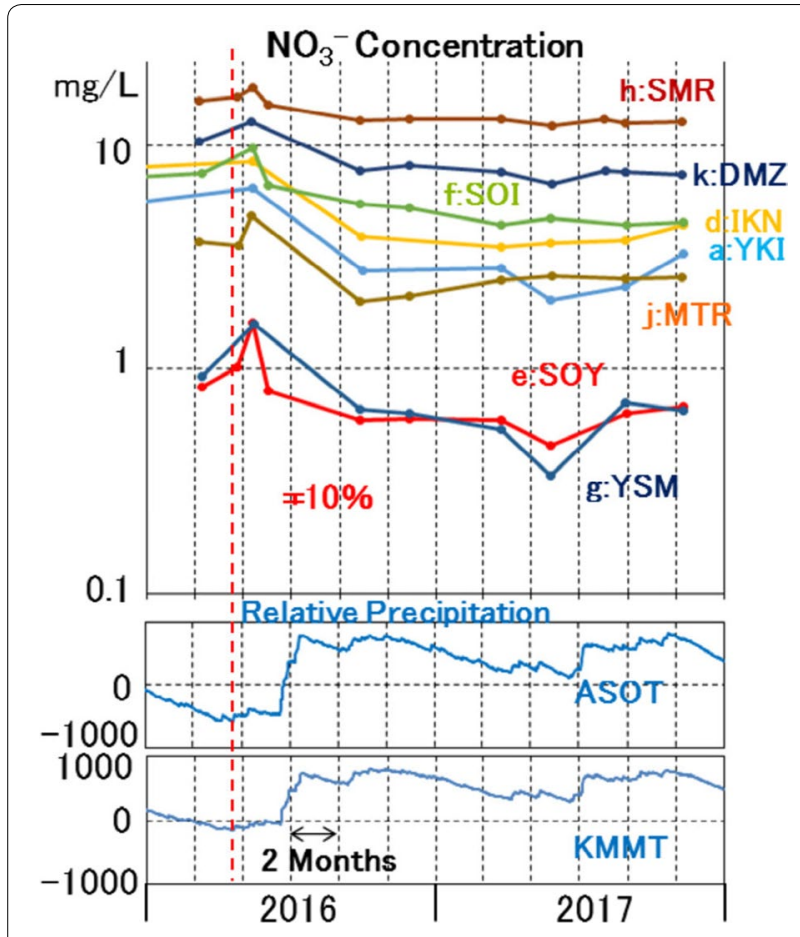

Fig. 10 Temporal change in $\mathrm{NO}_{3}{ }^{-}$concentration at eight springs. Before 2016 at a:YKI, d:IKN, and f:SOI, the $\mathrm{NO}_{3}{ }^{-}$concentration was, respectively, measured on February 1, 2014; September 6, 2014; and February 1,2014 . The precision is about a few to $10 \%$. Vertical red broken line indicates the occurrence of the main shock of the 2016 Kumamoto earthquake

\section{Acknowledgements}

We thank Dr. K. Osaka for his helpful advice. We also thank Dr. K. Kawabata for her cooperation during the field surveys in Kumamoto Prefecture. We thank the residents of Kumamoto Prefecture for their cooperation in this research. We are grateful to the two anonymous reviewers for reviewing our manuscript and valuable comments.

\section{Authors' contributions}

NK carried out the processing and analysis of groundwater and stream water data and drafted the manuscript. SM, TT, and AM carried out the data processing and analysis of the streamflow data. TA, TS, and HT carried out the groundwater observations and chemical analysis of the spring waters. NM helped draft the manuscript. All authors read and approved the final manuscript.

\section{Funding}

This work was supported by a Grant-in-Aid for Scientific Research on Innovative Areas (KAKENHI No. 26109006) from the Ministry of Education, Culture, Sports, Science and Technology.

\section{Availability of data and materials}

The sources of streamflow and precipitation data are listed in the references. The other data are available on request from NK.

\section{Ethics approval and consent to participate} Not applicable.

\section{Consent for publication}

Not applicable.

\section{Competing interests}

The authors declare that they have no competing interests.

\section{Author details}

${ }^{1}$ School of Environmental Science, The University of Shiga Prefecture, 2500, Hassaka-cho, Hikone, Shiga 522-8533, Japan. ${ }^{2}$ Taneya Co. Ltd, 615-1 Kitanosyo-cho, Omihachiman, Shiga 529-8533, Japan. ${ }^{3}$ JA Lake Otsu, Uchidehama 14-1, Otsu, Shiga 520-0806, Japan. ${ }^{4}$ Yodogawa Hu-Tech Co., Ltd.,, 2-4-8 Esaka, Suita, Osaka 564-0063, Japan. ${ }^{5}$ Kinki Eco Science Inc., 19-9 Kojoga-oka, Otsu, Shiga 520-0821, Japan. ${ }^{6}$ Geological Survey of Japan, AIST, C-7,1-1-1, Higashi, Tsukuba, Ibaraki 305-8567, Japan.

Received: 2 Auqust 2019 Accepted: 16 November 2019

Published online: 29 November 2019

\section{References}

Geospatial Information Authority of Japan (2019) Maps of geospatial information authority of Japan. http://maps.gsi.go.jp/. Accessed 17 Mar 2019

Hashimoto M, Savage M, Nishimura T, Horikawa H, Tsutsumi H (2017) Special issue "2016 Kumamoto earthquake sequence and its impact on earthquake science and hazard assessment". Earth Planets Space 69:98. https:// doi.org/10.1186/s40623-017-0682-7

Hirata N (2016) The 2016 Kumamoto earthquake, report of the coordinating committee for earthquake prediction research, vol 96, pp 490-491 (In Japanese)

Hosono T, Yamada C, Shibata T, Tawara Y, Wang C-Y, Manga M, Rahman ATMS, Shimada J (2019) Coseismic groundwater drawdown along crustal ruptures during the 2016 Mw7.0 Kumamoto earthquake. Water Resour Res 55:5891-5903. https://doi.org/10.1029/2019WR024871

Ichiyanagi K, Ando S (2017) River water level change affected by the Kumamoto earthquake. J Jpn Assoc Hydrol Sci 47:11-15 (in Japanese)

Japan Meteorological Agency (2019a) Estimated seismic intensity distribution map of Kumamoto Prefecture Kumamoto region M7.1 at 01:25 on April 16, 2016. https://www.data.jma.go.jp/svd/eew/data/suikei/2016041601 25_741/201604160125_741_1.html. Accessed 17 Mar 2019

Japan Meteorological Agency (2019b) Past weather data and download. http://www.data.jma.go.jp/gmd/risk/obsdl/index.php. Accessed 15 Jan 2019

Kawagoshi Y, Koga H, Suenaga Y, Hama T, Ito H (2018) Influence of the 2016 Kumamoto earthquake on groundwater quality, Japan. J Limnol 79:147-158

Manga M (2001) Origin of postseismic streamflow changes inferred from baseflow recession and magnitude-distance relations. Geophys Res Lett 28:2122-2136

Ministry of land, infrastructure, transport and tourism (2019) Water information system. http://www1.river.go.jp/. Accessed 17 Jan 2019 (in Japanese)

Miyabuchi Y (2016) Landslide disaster triggered by the 2016 Kumamoto earthquake in and around Minamiaso Village, Western Part of Aso Caldera, Southwestern Japan. J Geogr 125:421-429. https://doi.org/10.5026/jgeog raphy.125.421 (in Japanese)

Montgomery DR, Greenberg HM, Smith DT (2003) Streamflow response to the Nisqually earthquake. Earth Planet Sci Lett 209:19-28

Mosley MP (1979) Streamflow generation in a forested watershed, New Zealand. Water Resour Res 15:795-806

Rojstaczer S, Wolf S (1992) Permeability changes associated with large earthquakes: an example from Loma Prieta, California. Geology 20:211-214

Rojstaczer S, Wolf S, Michel R (1995) Permeability enhancement in the shallow crust as a cause of earthquake-induced hydrological changes. Nature 373:237-239

Sato T, Sakai R, Furuya K, Kodama T (2000) Coseismic spring flow changes associated with the 1995 Kobe earthquake. Geophys Res Lett 27:1219-1222

Sato T, Takahashi HA, Kawabata K, Takahashi M, Tosaki Y, Miyakoshi A, Inamura A, Handa H, Matsumoto N, Kazahaya K (2017) Anomalous changes in groundwater and hot spring water after the 2016 Kumamoto earthquake. In: Abstracts of JPGU-AGU joint meeting 2017, Makuhari Messe, Chiba, Japan, 20-24 May 2017 
Shirahama H, Yoshimi M, Awata Y, Maruyama T, Azuma T, Miyashita Y, Mori H, Imanishi K, Takeda N, Ochi T, Otsubo M, Asahina D, Miyakawa A (2016) Characteristics of the surface ruptures associated with the 2016 Kumamoto earthquake sequence, central Kyushu, Japan. Earth Planets Space. https://doi.org/10.1186/s40623-016-0559-1

Waller RM (1966) Effects of the March 1964 Alaska earthquake on the hydrology of south-central Alaska. USGS Professional Paper 544A, 28 p, https:// pubs.usgs.gov/pp/0544a/. Accessed 7 July 2019

Wang C-Y, Manga M (2015) New streams and springs after the 2014 Mw6.0 South Napa earthquake. Nat Commun. https://doi.org/10.1038/ncomm s8597
Wang C-Y, Wang C-H, Manga M (2004) Coseismic release of water from mountains: evidence from the $1999(\mathrm{Mw}=7.5)$ ChiChi, Taiwan, earthquake. Geology 32:769-772

\section{Publisher's Note}

Springer Nature remains neutral with regard to jurisdictional claims in published maps and institutional affiliations.

\section{Submit your manuscript to a SpringerOpen ${ }^{\circ}$ journal and benefit from:}

- Convenient online submission

- Rigorous peer review

- Open access: articles freely available online

- High visibility within the field

- Retaining the copyright to your article

Submit your next manuscript at $\boldsymbol{\nabla}$ springeropen.com 